\title{
Kardiyopulmoner Resusitasyona Yönelik YouTubeVideolarının Görselliğinin ve Bilgi İçeriğinin Değerlendirilmesi
}

\author{
Muaz Gülşen ${ }^{1} \oplus$, Neriman Akansel²®
}

${ }^{1}$ Çukurova Üniversitesi Sağlık Bilimleri Fakültes, Hemşirelik Bölümü Cerrahi Hastalıkları Hemşireliği Anabilim Dalı, Adana, Türkiye

2Uludağ Üniversitesi Sağlık Bilimleri Fakültesi, Hemşirelik Bölümü Cerrahi Hastalıkları Hemşireliği Anabilim Dalı, Bursa, Türkiye

Muaz Gülşen, Araş. Gör. Neriman Akansel, Doç. Dr.

Illetişim:

Araş. Gör. Muaz Gülşen

Çukurova Üniversitesi Sağlık Bilimleri Fakültes, Hemşirelik Bölümü Cerrahi Hastalıkları Hemşireliği Anabilim Dalı, Adana, Türkiye Tel: +903223386078

E-Posta: muaz.gulsen@gmail.com

\section{ÖZET}

Amaç: Bu çalışmanın amacı Türkçe YouTube sayfalarında kardiyopulmoner resusitasyon (CPR) uygulaması ilgili videoların 2015 CPR kılavuzuna uygunluğunun değerlendirilmesidir.

Gereç ve Yöntem: Tanımlayııı olarak tasarlanan bu çalışmanın verileri Ağustos- Ekim 2018 tarihleri arasında toplandı. YouTube arama motorunun Türkçe sayfalarında "kardiyopulmoner resüsitasyon", "temel yaşam desteği", "kalp masajı" anahtar kelimeleri kullanılarak arama yapıldı. Araştırma kriterlerine uyan videolar araştırmacılar tarafından oluşturulan bir kontrol listesi aracılığı ile görsellik ve bilgi içeriği yönünden değerlendirildi. Verilerin değerlendirilmesinde SPSS 20,00 programı kullanıldı, sonuçlar sayı ve yüzde olarak verildi.

Bulgular: İncelenen videoların \%81,6'sında hastanın tepkisinin nasıl kontrol edileceği, \%73,7'sinde işleme başlamadan önce 112 acil servisten yardım istenmesi gerektiğine yönelik bilginin yer aldığı, ancak \%73,7'sinde CAB sıralamasına uyulması gerektiğine vurgu yapmadığı belirlendi. CPR uygulama videoların \%63,2'sinde sağlık personeli tarafından anlatıldığı, videoların \%57,9'unun ilgi çekici olmadığı ve ilgiyi sürdüremediği görüldü. Videoların ortalama süresi 5,85 dk (ss: 4,35) olarak hesaplandı.

Sonuç: Kardiyopulmoner resusitasyon, solunum ya da dolaşım fonksiyonları durmuş, bilinci yerinde olmayan bireylere uygulandığında hızlı ve etkili bir uygulamadır. Özellikle eksiksiz ve etkin kullanıldığında mortalite ve morbiditeyi önemli derecede azaltmaktadır. CPR bilgi ve becerinin birlikte kullanıldığı bir uygulama olduğundan, kullanıımayan bilgilerin ve tekrarlanmayan uygulamaların hem uygulayıı hem de üzerinde uygulamanın yapıldığı kişi açııından ciddi sonuçlar doğurabileceği bir gerçektir. Bu çalışmadan elde edilen veriler doğrultusunda Türkiye'de Türkçe YouTube kanalında CPR uygulamasına yönelik bilgi edinmek isteyenlerin ulaşabileceği güncel, güvenilir, eksiksiz ve faydalı videoların sayısının oldukça sınırlı olduğu görülmektedir.

Anahtar sözcükler: Internet, YouTube, kardiyopulmoner resusitasyon, temel yaşam desteği, kalp masajı

EVALUATION OF VISUALITY AND INFORMATION CONTENT OF YOUTUBE VIDEOS RELATED TO CARDIOPULMONARY RESUSCITATION

\section{ABSTRACT}

Aim: The aim of this study was to evaluate the suitability of Turkish CPR YouTube videos with 2015 AHA guidelines.

Material and method: Data related to this descriptive study were collected between 15 August-15 0ctober 2018 by researchers. YouTube search engine was searched for the keywords " cardiopulmonary resuscitation", "basic life support", "cardiac massage". Videos applicable for research criteria were included in this study and were evaluated for visuality and content. Data were evaluated using SPSS 20.0, results were given in numbers and percentages.

Results: Most of the videos included information on checking the response of the patient (81.6\%) calling emergency help (73.7\%). However, $73.7 \%$ of the videos did not include the information on the CAB order. Sixty-three point two percent $(63.2 \%)$ of the CPR videos were presented by health care staff; more than half of them were not able to maintain attention. The main duration of the videos was calculated as 5.85 minutes (SD: 4.35)

Conclusion: CPR is an effective procedure for individuals with respiratory and cardiac arrest. If it is done sufficiently, it can reduce mortality and morbidity rates. Since doing CPR is a practice that requires both certain knowledge and skills; not using the related knowledge and the skills could raise some concerns both for the patient and for practitioners. According to the results of this study, it was determined that up to date, trustworthy and useful YouTube videos related to CPR are very limited on Turkish websites.

Keywords: Internet, YouTube, CPR, basic life support, cardiac massage
Gönderilme Tarihi : 08 Mart 2019

Revizyon Tarihi : 09 Nisan 2019

Kabul Tarihi : 11 Nisan 2019 
ardiyak arrest, solunum ve dolaşımın çeşitli sebeplerden dolayı beklenmedik ve ani bir şekilde durması olarak tanımlanmaktadır $(1,2)$. Kardiak arrestin meydana gelmesi durumunda ise, erken tanı ve müdahale bireylerin sağ kalım oranını artırmaktadır. Bu erken tanı ve müdahaledeki basamakların (olayın başlangıcından hastanın sağlık kurumuna nakil süreci) bütünü "Kardiyopulmoner Resusitasyon (CPR)" olarak sınıflandırılmaktadır (3). Toplumdaki bireylerin CPR konusunda eğitim alması, kardiyak arrest durumlarında olayın erken tanılanmasına ve zamanında müdahale edilmesine olanak tanır. Özellikle internette bu konuda hazırlanmış çok sayıda görseller ve videolar yer almaktadır. Formal bir eğitim olmamakla birlikte, internette yer alan videoların kişilerin bilgi ve uygulamalarında etkili olduğu, bilgiye ulaşmada "YouTube"un en fazla tercih edilen arama motorlarının başında geldiği bilinmektedir (4). Özellikle sağlıkla ilgili konuların internette en çok araştırılan konular arasında yer aldığı dikkate alındığında, kalp durması gibi acil bir durumda kişilerin doğru uygulamaları bilmesi ve bunları uygulayabilmesi son derece kritiktir (5).

Amerika Birleşik Devletleri'nde kardiyak arrestten dolayı gerçekleşen ölümlerin çoğu sağlık kurum ve kuruluşların dışında oluşmakta ve kardiayak arrest sonrasında hayatta kalma oranlarının da oldukça düşük (\%1-5) olduğu tahmin edilmektedir (6). Bir çalışmada da kardiyak arrestten kaynaklanan ölümlerin bireylerin yaşadıkları yerlerde ve gündüz saatlerinde (08-18:00) meydana geldiği belirlenmiştir $(2,7)$. Literatürde YouTube sayfalarında bulunan kardiyopulmoner resusitasyon uygulama videolarını ve bu videoların Amerikan Kalp Derneği'nin (American Heart Association - AHA) 2015 yılında yayınladığı güncel kılavuzlara uygunluğunu değerlendiren sınırlı sayıda araştırma bulunmaktadır (8-10). Bu çalışmanın amacı, Türkçe YouTube sayfalarında yer alan yetişkin CPR videolarının 2015 CPR kılavuzuna uygunluğunu değerlendirmektir.

\section{Gereç ve Yöntem}

Tanımlayıcı olan bu çalışmanın verileri 15 Ağustos-15 Ekim 2018 tarihleri arasında toplandı. Türkiye'de en çok kullanılan YouTube video sayfalarında "Kardiyopulmoner Resusitasyon”, “Temel Yaşam Desteği”, “Kalp Masajı” anahtar kelimeleri ile Türkçe dilinde arama yapıldı. Uygun anahtar kelimelerle arama yapıldığında 128 videoya ulaşıldı. İncelenen videoların 90 tanesi (çocuk/yeni doğan temel yaşam desteği ve 2015 yılından önce yayınlanan videolar) araştırma kriterlerine uygun olmadığından araştırmaya dâhil edilmedi ve 38 video değerlendirildi (Şekil 1). Videoların değerlendirilmesinde araştırmacılar tarafından

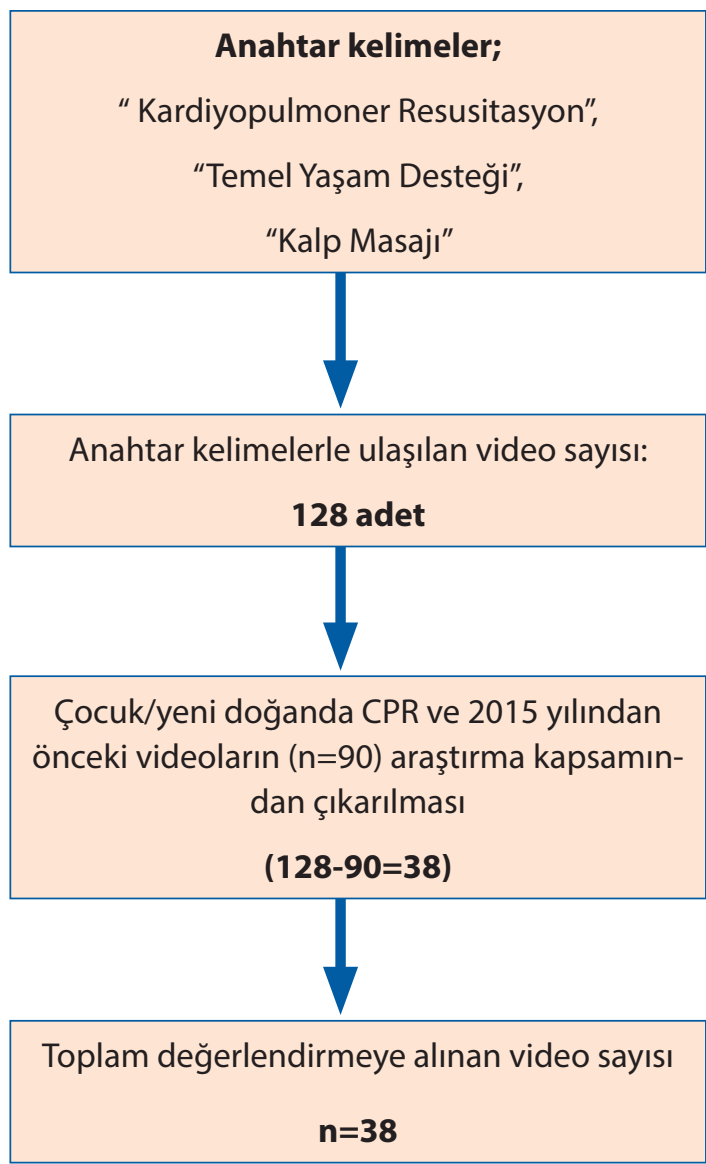

Şekil 1. Veri toplama süreci ve aşamaları.

güncel 2015 Kardiyopulmoner Resüsitasyon uygulama rehberi doğrultusunda videoların bilgi içeriğini (14 soru) ve genel tasarımı (11 soru) değerlendiren sorulardan oluşan bir kontrol listesi kullanıldı. Veriler IBM SPSS 20.00 programında değerlendirildi sonuçlar sayı, yüzde, ortalama ve standart sapma şeklinde verildi.

\section{Bulgular}

YouTube sayfalarında Türkçe CPR videoları değerlendirildiğinde; ortamın ilkyardımcı ve kazazede için güvenli olması gerektiği videoların yarısından fazlasında yer aldığı $(\% 52,6)$ görüldü. Videoların önemli bir kısmında hastanın tepkisinin kontrol etme $(\% 81,6)$, soluk alıp verme ve nabız değerlendirmesi yapma $(\% 68,4)$, işleme başlamadan önce 112 acil servisten yardım istenmesi gerektiğine $(\% 73,7)$ vurgu yapıldığı belirlendi. Videoların \%73,7'sinde CAB (dolaşım, açık hava yolu sağlama, solunumu sürdürme) sırasına vurgu yapılmadığı ve \%97,4'ünde sağlık personeli olmayan uygulayıcıların CPR uygulamasını suni solunum yapmadan da sürdürebileceğine yönelik bir açıklamanın olmadığı belirlendi. YouTube videolarında temel yaşam desteğine ilişkin bilgilerin içeriği Tablo 1'de verilmektedir. 
Videoların tasarımında; \%92,1'inde tıbbı terminolojinin yer almadığı, \%97,4'ünde tıbbi terminoloji bilgisini olmayan kişilerin anlayacağı şekilde tasarlandığı belirlendi. CPR uygulama videoların \%63,2'sinde sağlık personeli tarafından anlatıldığı, videoların \%57,9'unun ilgi çekici olmadığı ve ilgiyi sürdüremediği görüldü. Videoların ortalama süresi 5,85 dk (ss: 4,35) olarak hesaplandı (Tablo 2).

\section{Tartışma}

CPR uygulamaları periyodik aralıklarla (her beş yılda bir) güncellenmekte ve yenilenmektedir. Amerikan Kalp Derneğinin (AHA) en son CPR kılavuzu güncellemesi 2015 yılında yapılmıştır (11). Kardiyopulmoner resusitasyon, solunum ya da dolaşım fonksiyonları durmuş, bilinci yerinde olmayan bireylere uygulandığında hızlı ve etkili bir uygulamadır. Özellikle eksiksiz ve etkin kullanıldığında mortalite ve morbiditeyi önemli derecede azaltmaktadır (12). CPR

Tablo 1. Youtube videolarında temel yaşam desteğine ait bilgilerin içeriği

\begin{tabular}{|c|c|c|c|c|}
\hline \multirow[b]{2}{*}{ IÇERIK } & \multicolumn{2}{|c|}{ Evet } & \multicolumn{2}{|c|}{ Hayır } \\
\hline & $n$ & $\%$ & $n$ & $\%$ \\
\hline $\begin{array}{l}\text { Ortamın ilkyardımcı ve kazazede için } \\
\text { güvenli olması gerekliliginden bahsediyor mu? }\end{array}$ & 20 & 52,6 & 18 & 47,4 \\
\hline $\begin{array}{l}\text { Hastanın tepkisinin nasıl kontrol edileceği } \\
\text { açıklanıyor mu? (Omzuna dokunarak...) }\end{array}$ & 31 & 81,6 & 7 & 18,4 \\
\hline $\begin{array}{l}\text { Soluk alıp vermeyi, nabzı değerlendirmeyi } \\
\text { gösteriyor mu? } \\
10 \text { sn'den daha az sürede değerlendirmeye } \\
\text { vurgu yapıyor mu? (sağlık personeli için) }\end{array}$ & 26 & 68,4 & 12 & 31,6 \\
\hline $\begin{array}{l}\text { İşleme başlamadan önce yardım istenmesi } \\
\text { (112 aranması, birinin yardım çağırması) } \\
\text { gerektiğini söylüyor mu? }\end{array}$ & 28 & 73,7 & 10 & 26,3 \\
\hline CAB kuralına vurgu yapıyor mu? & 10 & 26,3 & 28 & 73,7 \\
\hline $\begin{array}{l}\text { Sağllk Personeli olmayan kişiler ve ilkyardım } \\
\text { eğitimi almayanların sadece kalp masajı ile } \\
\text { devam edebileceğine vurgu yapıyor mu? }\end{array}$ & 1 & 2,6 & 37 & 97,4 \\
\hline $\begin{array}{l}\text { Göğüs basısı yapılacak yer ve ellerin } \\
\text { pozisyonunu açıklıyor mu? }\end{array}$ & 28 & 73,7 & 10 & 26,3 \\
\hline $\begin{array}{l}\text { Bası derinliğinin en az } 5 \mathrm{~cm} \text { olması gerektiğini } \\
\text { söylüyor mu? }\end{array}$ & 21 & 55,3 & 17 & 44,7 \\
\hline $\begin{array}{l}\text { Bası derinliğinin en fazla } 6 \mathrm{~cm} \text { olması gerektiğini } \\
\text { söylüyor mu? }\end{array}$ & 3 & 7,9 & 35 & 92,1 \\
\hline $30 / 2$ yöntemine vurgu yapıyor mu? & 34 & 89,5 & 4 & 10,4 \\
\hline $\begin{array}{l}\text { Sayarken v1, v2, v3... Sayma yönteminden } \\
\text { bahsediyor mu? (10'a kadar olan sayllarda) }\end{array}$ & 21 & 55,3 & 17 & 44,7 \\
\hline $\begin{array}{l}\text { CPR de tek ya da çift kişi kurtarıcı olması } \\
\text { durumunda kalp masajı ve suni solunum } \\
\text { oranında bir fark olmadığını açıklıyor mu? }\end{array}$ & 3 & 7,9 & 35 & 92,1 \\
\hline $\begin{array}{l}\text { Göğüs kompresyonu sayısının 100-120/dk } \\
\text { olması gerektiğini açıklıyor mu? }\end{array}$ & 13 & 34,2 & 25 & 65,8 \\
\hline $\begin{array}{l}\text { TYD'nin sonlandırma kriterlerinden } \\
\text { bahsediyor mu? }\end{array}$ & 23 & 60,5 & 15 & 39,5 \\
\hline
\end{tabular}

Tablo 2. Temel yaşam desteğine yönelik you tube videolarının tasarımına ilişkin özellikler

\begin{tabular}{lcc} 
& Evet & Hayır \\
\hline TASARıM & $\boldsymbol{n}(\%)$ & $\boldsymbol{n}(\%)$ \\
\hline Video anlatımında tıbbı terminoloji var mı? & $3(7,9)$ & $35(92,1)$ \\
Video halktan bir kişinin anlayabileceği şekilde mi & $37(97,4)$ & $1(2,6)$ \\
tasarlanmış? & & \\
Anlatım maketle mi yapılıyor? & $30(78,9)$ & $8(21,1)$ \\
Anlatımda slayt sunumu var mı? & $6(15,8)$ & $32(84,2)$ \\
Anlatım ilgi çekici mi ve bunu sürdürebiliyor mu? & $16(42,1)$ & $22(57,9)$ \\
Temel yaşam desteğini anlatan sağlık & $24(63,2)$ & $14(36,8)$ \\
personeli mi? & & \\
& $\mathbf{0 r t} \pm \mathbf{S S}$ \\
Tıklanma sayıSı & $9185 \pm 3268$ \\
Beğenilme sayısı & $58,50 \pm 242,11$ \\
Beğenilmeme sayısı & $6,81 \pm 22,50$ \\
Videonun süresi (dk) & $5,85 \pm 43,53$
\end{tabular}

bilgi ve becerinin birlikte kullanıldığı bir uygulama olduğundan, kullanılmayan bilgilerin ve tekrarlanmayan uygulamaların hem uygulayıı hem de üzerinde uygulamanın yapıldığı kişi açısından ciddi sonuçlar doğurabileceği bir gerçektir (13). Konu ile ilgili yapılan bazı çalışmalarda CPR eğitimi almış bireylerin yetersiz ve yanlış bilgilere sahip olduğu görülmektedir (14-17). Yoldaş ve ark'nın (2016) yapmış olduğu çalışmada doktorların CPR bilgisinin istenen seviyede olmadığı görülmüştür (18).

Çalışmamızda incelenen videolarda CPR uygulamasında ilkyardımcı ve kazazede için uygun ortam oluşturulması, hastanın tepkisini nasıl kontrol edileceği, soluk alıp verme ve nabız değerlendirmesi, 112 'den yardım istenmesi gibi önemli basamakların videoların bir kısmında yer almadığı görülmektedir. İlkyardımcının sağlık personeli olmaması durumunda suni solunum yapmadan ilkyardım ekibi gelene kadar sadece kalp masajıyla sürdürebileceğine ilişkin açıklama $(\% 2,6)$ ile CAB sıralamasına yönelik bilgi çok az sayıdaki videoda $(\% 26,3)$ yer almaktadır. CAB (dolaşımı sürdürme, hava yolu açıklığını sağlama ve solunumu sürdürme) sıralaması ilk kez 2015 CPR kılavuzunda yer verilmiş ve halen geçerli olan en temel ayrıntılardan bir tanesidir (19). Birçok sağlık çalışanın hava yolu açıklığı sağlama (erken entübasyon) sırasında kardiyak kompresyonu başlatmada gecikmenin, olumsuz sonuçlar doğurması nedeni ile öncelikli olarak kardiyak kompresyona yer verilmesi son derece kritiktir. Hayat zinciri olarak tanımlanan bu basamakların birbirine bağlı olması nedeni ile sıralamaya uyulması önemlidir. En zayıf basamağın uygulamanın etkinliğini 
doğrudan etkilediği öngörülmektedir (19). Benzer şekilde Aygin ve ark. (2018) hemşirenin CPR uygulaması hakkında bilgi düzeylerini değerlendirdikleri çalışmada, hemşirelerin \%26,8'inin CAB sırasını bilmedikleri saptanmıştır. Aynı çalışmada hemşirelerin \%23,7'sinin göğüs kompresyon hızının ne kadar olması gerektiği, \%10,3'ünün kompresyon derinliğinin (en az beş $\mathrm{cm}$ en fazla altı $\mathrm{cm}$ olması gerektiği) ne olması gerektiği hakkında güncel bilgiye sahip olmadıkları belirlenmiştir (20).

$\mathrm{Bu}$ çalışmada incelenen videoların önemli bir kısmında ellerin pozisyonunun nasıl olması gerektiği $(\% 73,7)$ bilgisi ile yarıdan fazlasında $(\% 55,3)$ bası derinliğinin en az beş $\mathrm{cm}$ olması gerektiğine vurgu yapılmıștır. Önemli bir ayrıntı olmakla birlikte bası derinliğin en fazla kaç $\mathrm{cm}$ olması gerektiği videoların sadece \%7,9'unda yer almaktadır. Kalp masajı/suni solunum sayısı oranının 30/2 olması gerektiği videoların tamamına yakınında vurgulanmıştır. Ancak bu uygulamanın tek ya da çift kişiyle yapıımasının kalp masajı/ suni solunum oranını değiştirmeyeceği videoların önemli bir bölümünde $(\% 92,1)$ açıklanmamıştır. Kalp masajının dakikada 100-120 arasında olması gerektiği 2015 AHA kılavuzunda yeni değişen önemli bir ayrıntıdır ancak araştırmamızda incelenen videoların \%65,8'de yer almamaktadır. CPR uygulamasındaki oranlar ve sayısal ayrıntılar AHA'nın (2015) güncel kılavuzunda en fazla vurgulanan alanlar arasındadır $(13,19)$. Sağlık çalışanlarının bile CPR uygulamalarının belli aşamalarında eksiklerinin olduğu düşünüldüğünde YouTube videolarını izleyerek bilgi sahibi olan ve uygulayabileceğini düşünen kişiler toplum için önemli bir tehlike oluşturacağı düşünülmektedir. Bu nedenle sağlığa ilişkin bilgilerin halka sade ve net bir şekilde anlatılması konunun daha iyi anlaşılması ve hataların önlenmesi açısından önemlidir (21). Çalışmamızda videolardaki en önemli eksikliklerden bir tanesi de ilkyardımcı eğer suni solunum yapmayı bilmiyorsa ya da nasıl yapacağından emin değilse, yardım gelinceye kadar sadece kalp masajı ile devam edebileceğine ilişkin bilgiye sadece bir videoda yer verilmesidir.

Brown ve ark.'nın (2018) son dönem böbrek yetmezliği olan hasta ve ailelerinin CPR'ye karar verme ve uygulama becerisi açısından değerlendirildiğinde video izletilen gruptakilerin uyulama puanlarının daha yüksek olduğu belirlenmiştir (22). CPR uygulamasının video kullanılarak ve simülasyon eğitimi ile anlatıldığı gruplarda beceri artışının daha fazla olduğu belirlenmiştir $(10,23)$.

Konu ile ilgili videoların değerlendirildiği çalışmalarda CPR uygulamasını anlatan kişilerin sağlık personeli olmadığı görülmektedir $(4,8,9)$. Bu çalışmada değerlendirilen videolarının bir kısmının $(\% 36,8)$ sağlık personeli tarafından anlatmadığı belirlenmekle birlikte daha önceki çalışmalardan düşük bir orandadır. Sağlık çalışanı dışındakilerin CPR uygulamasını anlatması, halktan insanların da CPR uygulamasını yapabileceklerine yönelik bir mesajı aktarmada olumlu görülmekle birlikte, hatalı uygulamaların öğretilmesi durumunda bir dezavantajdır. Benzer şekilde kritik noktaların vurgulanmaması da ciddi hayati riskler taşıyabilir. Araştırmalarda CPR uygulamasının anlatıldığı videoların sıklıkla televizyon (TV) programları olduğu görülmektedir (4). Bu durum TV programlarının halk tarafından yoğun olarak izlenmesine bağlanabilir.

YouTube kanalı üzerinden videolu eğitimin anlatılan konuyu daha eğlenceli hale getirdiği, konuyu daha net kavramaya yol açtığı ve uygulamada başarı oranını artırdığı belirtilmektedir (24). Bununla birlikte uygulamaya dayanan becerilerin kazandırılmasında sadece görmek yeterli bir yöntem değildir. Kazandırılması istenen becerinin önce eğitimci tarafından gösterilmesi ve öğrenenlere tekrarlatılması en etkin yoldur. Videolar, uygulayıcılara uygulamayı tekrar etme fırsatı sağlamasa da, uygulamanın maket üzerinde yapılması görsellik kazandırma ve kavramayı kolaylaştırma açısından son derece önemlidir. Araştırma kapsamında değerlendirilen videoların önemli bir kısmında maket kullanıldığı görülürken \%21,1'de maketin bulunmadığı görülmektedir. Bu sonuç, Yaylacı ve ark. (2015) çalışmasında maket kullanılmayan videoların oranını \%12,7 buldukları çalışmadan yüksektir (4). Ayrıca videoların \%84,2'sinde slayt sunumu gibi farklı bir görsele yer verilmediği belirlenmiştir. Videoların izlenme ve beğenilme sayılarına ilişkin verileri bir kriter olarak ele alındığında YouTube videolarının ne kadar önemsendiğini görmek mümkündür. Bu çalışmada videoların izlenme ortalaması 9185 olarak bulunmuştur. Yaylacı ve ark. (2015) çalışmasında bu sayı 1951'dir (4).

Bu çalışmadan elde edilen veriler doğrultusunda Türkiye'de Türkçe YouTube kanalında CPR uygulamasına yönelik bilgi edinmek isteyenlerin ulaşabileceği güncel, güvenilir, eksiksiz ve faydalı videoların sayısının oldukça sınırlı olduğu görülmektedir. Video kullanıcılarına yönelik yürütülecek çalışmalarla videoların faydalı olup olmadığının değerlendirilmesi medyadaki bilgi kirliliğinin azaltılmasına katkı sağlayabilir. Yüklenen videoların değerlendirilme olanağı bulunmadığından toplumun konu ile ilgili farkındalığının oluşturulması, özellikle sağlık alanındaki yanlış uygulamaların önüne geçilmemesine yardımcı olabilir. 


\section{Kaynaklar}

1. Türkmen E, Işık I, Balcı S, Akkuş Topçu S, Abalı S, Karaçay P. Temel Yaşam Desteği Kursuna Katılan Hemşirelik/Sağlık Yüksekokulu Öğrencilerinin Kurstaki Başarı, Beklenti ve Memnuniyetleri. Yoğun Bakım Hemşireliği Derg 2009;13:55-62. http://static.dergipark.org. tr/article-download/d2e9/fa49/80b7/imp-JA33UY95BJ-0.pdf?

2. Deo R, Albert CM. Epidemiology and Genetics of Sudden Cardiac Death. Circulation 2012;125:620-37. [CrossRef]

3. Field JM, Hazinski MF, Sayre MR, Chameides L, Schexnayder SM, Hemphill R, et al. Part 1: Executive Summary: 2010 American Heart Association Guidelines for Cardiopulmonary Resuscitation and Emergency Cardiovascular Care. Circulation 2010;122:640-56. [CrossRef]

4. Yaylacı S, Serinken M, Eliçabuk H, Yılmaz A, Dal O, Kaya GF, Youtube Kaynaklı Türkçe "Temel Yaşam Desteği" ve "Kalp Masajı"Videolarının Güvenilirliği. Gaziosmanpaşa Üniversitesi Tıp Fakültesi Derg 2014;6:126-32.

5. Yaylacı S, Serinken M, Eken C, Karcıoğlu Ö, Yılmaz A, Elicabuk H, Dal $O$. Are YouTube videos accurate and reliable on basic life support and cardiopulmonary resuscitation? Emerg Med Australas 2014;26:4747. [CrossRef]

6. Marenco JP, Wang PJ, Link MS, Homound MK, Estes MNA 3rd. Improving Survival From Sudden Cardiac Arrest. The role of the Automated External Defibrillator. JAMA 2011;285:1193-200. [CrossRef]

7. Priori SG, Alliot E, Blømstrom-Lundqvist C, Bossaert L, Breithardt G, Brugada P, et al. Ani Kardiyak Ölüm. Avrupa Kardiyoloji Derneği Çalışma Grubu ESC Kılavuzu, Türk Kardiyoloji Derneği. Adalet K, Gürdal M, Mutlu B, çeviri editörleri. France: Eur Soc Cardiol 2003:1-30.

8. Elicabuk H, Yaylacı S, Yılmaz A, Hatipoğlu C, Kaya FG, Serinken M. The Reliability of Turkish "Basic Life Support" and "Cardiac Massage" Videos Uploaded to Websites. Eurasian J Med 2016;48:15-9. [CrossRef]

9. Beydilli $H$, Serinken M, Eken C, Elicabuk H, Dal O, Acar E, et al. The Validity of YouTube Videos on Pediatric BLS and CPR. Telemed J E Health 2016;22:165-8. [CrossRef]

10. Beskind LD, Stolz U, Thiede R, Hoyer R, Burns W, Brown J, et al. Viewing a brief chest-compression-only CPR video improves bystander CPR performance and responsiveness in high school students: A cluster randomized trial. Resuscitation 2016;104:28-33. [CrossRef]

11. Katırcı Y. Temel Yaşam Desteği 2015 Update, Amerikan Kalp Derneği (AHA) Kılavuzunda öne çıkan noktalar; 2016. http://file.atuder.org. tr/_atuder.org/fileUpload/LXS9kSzvIWTC.pdf

12. Soysal S, Karcıoğlu Ö, Korkmaz T, Topaçoğlu H. Temel yaşam desteği eğitimi: ideal ne kadar uzakta? Akademik Acil Tıp Derg 2009;40-6.

13. Perkins DG, Handley JA, Koster WR, Castrén $M$, Smyth AM, Olasveengen $T$, et al. European Resuscitation Council Guidelines for Resuscitation 2015: Section 2. Adult basic life support and automated external defibrillation. Resuscitation 2015;95:81-99. [CrossRef]
14. Rajeswaran L, Ehlers VJ. Cardiopulmonary Resuscitation Knowledge and Skills of Registered Nurses in Botswana. Curationis 2014;37:1-7. [CrossRef]

15. Gebremedhn EG, Gebregergs GB, Anderson BB, Nagaratnam V. Attitude and skill levels of graduate health professionals in performing cardiopulmonary resuscitation. Adv Med Educ Pract 2017;8:43-50. [CrossRef]

16. Preusch MR, Bea F, Roggenbach J, Katus HA, Jünger, J, Nikendei $C$. Resuscitation Guidelines 2005: does experienced nursing staff need training and how effective is it? Am J Emerg Med 2010;28:477-84. [CrossRef]

17. Yıldırım A, Kiraz HA, Bayezit A, Bağcı M, Akdur O. Kardiyopulmoner Resüsitasyon Uygulamalarındaki Değişikliklerin Farkındalığı; Bir Anket Çalışması. STED 2016;25:1-5. https://www.ttb.org.tr/STED/ images/files/dergi/2016/1.pdf

18. Yoldaş H, Kocoğlu H, Bayır H, Yıldızi, Akkaya A, Demirhan A, Tekelioğlu ÜY. Attitudes of Doctors Working in Abant Izzet Baysal University Health Research and Application Center on Cardiopulmonary Resuscitation. Turk J Anaesthesiol Reanim 2016;44:142-8. [CrossRef]

19. Kleinman EM, Brennan EEC, Goldberger DZ, Swor AR, Terry M, Bobrow JB, et al. Part 5: Adult Basic Life Support and Cardiopulmonary Resuscitation Quality 2015 American Heart Association Guidelines Update for Cardiopulmonary Resuscitation and Emergency Cardiovascular Care. Circulation 2015;132:S414-35. [CrossRef]

20. Aygin D, Açıl CH, Yaman Ö, Çelik M, Danç E. Hemşirelerin Kardiyopulmoner Resüsitasyon ve Güncel 2015 Kılavuz Bilgilerinin Değerlendirilmesi. Turk J Cardiovasc Nurs 2018;9:7-12. [CrossRef]

21. İşleyen F, Gülkesen KH, Zayim N. Türkçe Web Sitelerinde Sunulan Sağlık Bilgisinin Anlaşılırlığı 2. Ulusal Tıp Bilişimi Kongresi / Medikal Informatics 2005:140-4. https://turkmia.net/kongre/cd/pdf/28.pdf

22. Brown KC, Kryworuchko J, Martin W. Evaluation of the CPR video decision aid with patients with end stage renal disease. BMC Nephrology 2018;19:226. https://bmcnephrol.biomedcentral.com/ articles/10.1186/s12882-018-1018-y

23. Öztürk D, Gürol A, Uslu S, Yücel O. The Effect of Essential Skills of Ambulance Simulation Laboratory Education to the First Aid and Emergency Program's Students. Arc Health Sci Res 2017;4:25-31. [CrossRef]

24. Alp Y, Kaleci D. Student Views Regarding the Usage of Videos on Youtube Website as a Training Material. Int J Active Learning - JJAL 2018;3:57-68. https://www.researchgate.net/ publication/328759457_YouTube_Sitesindeki_Videolarin_Egitim_ Materyali_Olarak_Kullanimina_lliskin_Ogrenci_Gorusleri_Student Views_Regarding_the_Usage_of_Videos_on_Youtube_Website_ as_a_Training_Material 